\title{
Relation of New and Old Formulas for Estimating Creatinine Clearance among Stroke Survivors
}

\author{
Bruce Ovbiagele \\ Stroke Center and Department of Neurology, UCLA Medical Center, Los Angeles, Calif., USA
}

\author{
Key Words \\ Kidney disease $\cdot$ Stroke $\cdot$ Risk factors $\cdot$ National Health \\ and Nutrition Examination Survey • Creatinine clearance • \\ Glomerular filtration rate
}

\begin{abstract}
Objective: To assess whether the newly proposed formula for estimating glomerular filtration function (GFR) - the Chronic Kidney Disease Epidemiology (CKD-EPI) equation would be materially distinct from the established Modification of Diet in Renal Disease (MDRD) equation in diagnosing chronic kidney disease (CKD) among US stroke survivors. Materials and Methods: Data from the National Health and Nutrition Examination Survey from 1999-2004, a nationally representative sample of adults from the United States, were used to assess the correlation between the MDRD and CKDEPI equations among persons aged $\geq 55$ years who had experienced a prior stroke. CKD was defined as GFR $<60 \mathrm{ml} /$ min/1.73 m². Results: Among 6,382 adults, 5,321 (83\%) had full and complete data. With MDRD, $20.4 \%$ of the sample had CKD vs. $19.4 \%$ using the CKD-EPI. There was $97.7 \%$ agreement between MDRD and CKD-EPI using the $60 \mathrm{ml} / \mathrm{min} /$ $1.73 \mathrm{~m}^{2}$ cutoff point. The correlation between both equations was extremely high $(r=0.954)$. Conclusion: The newly developed CKD-EPI equation is very highly correlated to the more established MDRD formula and does not materially change CKD diagnosis made by the latter among persons with a history of stroke.

Copyright $\odot 2010$ S. Karger AG, Basel
\end{abstract}

\section{Introduction}

International consensus guidelines indicate that accurate identification of undiagnosed chronic kidney disease (CKD) could allow the initiation of treatments targeted at limiting further renal function deterioration, as well as reduce the risk of untoward vascular sequelae, including stroke $[1,2]$. The widely recommended Modification of Diet in Renal Disease (MDRD) formula for calculating estimated glomerular filtration rate (GFR) or creatinine clearance, has been in use for 10 years $[2,3]$. However, in May 2009, a new equation for estimating GFR, known as the Chronic Kidney Disease Epidemiology Collaboration (CKD-EPI) Equation, was published, and it was suggested the CKD-EPI could replace the MDRD equation [4]. However, it is not clear whether GFR calculated by the newly proposed CKD-EPI equation would materially change CKD diagnosis made using the old formula [5]. This study aimed to assess the correlation between the MDRD and CKD-EPI formulas.

\section{Materials and Methods}

Data of subjects aged 55 and older, who participated in the National Health and Nutrition Examination Surveys (NHANES), a nationally representative sample of the civilian, noninstitutionalized US population from 1999 to 2004, were analyzed. Full details on NHANES procedures are published elsewhere [5]. This age cutoff has been used previously to reduce the proportion of per-

\section{KARGER \\ Fax +4161306 1234 \\ E-Mail karger@karger.ch}

www.karger.com
(C) 2010 S. Karger AG, Basel

$1011-7571 / 10 / 0194-0319 \$ 26.00 / 0$

Accessible online at:

www.karger.com/mpp
Bruce Ovbiagele, MD, MS

Stroke Center and Department of Neurology

University of California at Los Angeles

710 Westwood Plaza, Los Angeles, CA 90095 (USA)

Tel. +1 310794 6379, Fax +1 3102672063 , E-Mail ovibes@ mednet.ucla.edu 
Table 1. Summary statistics of formulas for estimating GFR in a nationally representative (United States) sample of individuals aged $\geq 55$ years

\begin{tabular}{|c|c|c|c|c|c|c|c|c|c|}
\hline GFR formula & $\mathrm{n}$ & Minimum & Lower quartile & Median & Mean & Upper quartile & Maximum & SD & SE \\
\hline MDRD & 5,321 & 3.26 & 60.24 & 72.92 & 73.37 & 85.65 & 307.60 & 21.11 & 0.29 \\
\hline CKD-EPI & 5,321 & 2.83 & 61.20 & 75.84 & 73.77 & 88.70 & 154.45 & 19.57 & 0.27 \\
\hline
\end{tabular}

sons with strokes due to very unusual causes often seen at younger ages [5]. This analysis accounted for stratification, clustering and weighting according to the NHANES Analytic and Reporting Guidelines [6]. GFR was first calculated using the MDRD formula taken from the National Kidney Disease Education Program website: www.nkdep.nih.gov/professionals. Abnormal GFR was defined as GFR $<60 \mathrm{ml} / \mathrm{min} / 1.73 \mathrm{~m}^{2}$. GFR was calculated using the newly proposed CKD-EPI formula [4]. Strokes comprised both ischemic and hemorrhagic strokes.

\section{Results}

Among 6,382 adults surveyed ( $\geq 55$ years of age), 5,321 (83\%) responded to the interview question about stroke and had valid laboratory information on serum creatinine. Table 1 shows the summary statistics for GFR values calculated by both equations, with median and mean values fairly close to each other. Comparative frequencies for estimated GFR values $\geq 60 \mathrm{ml} / \mathrm{min} / 1.73 \mathrm{~m}^{2}$ and $<60 \mathrm{ml} /$ $\mathrm{min} / 1.73 \mathrm{~m}^{2}$ by the MDRD and CKD-EPI equations showed similar values between both equations. Using the $60 \mathrm{ml} / \mathrm{min} / 1.73 \mathrm{~m}^{2}$ cutoff point, there was $97.7 \%$ agreement $[(1,209+3,991) / 5,321]$, and assessment of the correlation between both equations showed an extremely high correlation $(\mathrm{r}=0.954)$.

\section{Discussion}

Several laboratories around the country routinely report estimated GFR using the established MDRD formula along with serum creatinine to enhance early detection of CKD as recommended by the National Kidney Disease Education Program, National Kidney Foundation and the American Society of Nephrology [7]. This brief analysis observed a high degree of correlation between MDRD and the newly proposed CKD-EPI formula, which may suggest the new formula may not necessarily add substantial value to discriminating CKD in routine clinical practice.

\section{Conclusion}

Compared to the established formula, utilizing the newly proposed formula may not substantially change estimates of the prevalence of CKD among US stroke survivors or display a stronger association of CKD with stroke occurrence.

\section{References}

1 Baumelou A, Bruckert E, Bagnis C, Deray G: Renal disease in cardiovascular disorders: an underrecognized problem. Am J Nephrol 2005;25:95-105.

$>_{2}$ Brosius FC 3rd, Hostetter TH, Kelepouris E, Mitsnefes MM, Moe SM, Moore MA, Pennathur S, Smith GL, Wilson PW, American Heart Association Kidney and Cardiovascular Disease Council; Council on High Blood Pressure Research; Council on Cardiovascular Disease in the Young; Council on Epidemiology and Prevention; Quality of Care and Outcomes Research Interdisciplinary Working Group: Detection of chronic kidney disease in patients with or at increased risk of cardiovascular disease: a science advisory from the American Heart Association Kidney And Cardiovascular Disease Council; the
Councils on High Blood Pressure Research, Cardiovascular Disease in the Young, and Epidemiology and Prevention; and the Quality of Care and Outcomes Research Interdisciplinary Working Group: developed in collaboration with the National Kidney Foundation. Circulation 2006;114:1083-1087.

-3 Levey AS, Bosch JP, Lewis JB, Greene T, Rogers N, Roth D: A more accurate method to estimate glomerular filtration rate from serum creatinine: a new prediction equation. Modification of Diet in Renal Disease Study Group. Ann Intern Med 1999;130:461-470.

-4 Levey AS, Stevens LA, Schmid CH, Zhang YL, Castro AF, Feldman HI, Kusek JW, Eggers P, Van Lente F, Greene T, Coresh J, CKDEPI (Chronic Kidney Disease Epidemiology Collaboration): A new equation to estimate glomerular filtration rate. Ann Intern Med 2009;150:604-612.

5 Ovbiagele B: Impairment in glomerular filtration rate or glomerular filtration barrier and occurrence of stroke. Arch Neurol 2008; 65:934-938.

6 National Center for Health Statistics: National Health and Nutrition Examination Survey. http://www.cdc.gov/nchs/nhanes. htm (accessed January 1, 2007).

7 Levey AS, Coresh J, Balk E, Kausz AT, Levin A, Steffes MW, Hogg RJ, Perrone RD, Lau J, Eknoyan G: National Kidney Foundation practice guidelines for chronic kidney disease: evaluation, classification, and stratification. Ann Intern Med 2003;139:137-147. 